This is the postprint version of the following article: Saa, L; Diez-Buitrago, B; Briz, N; Pavlov, V CdS quantum dots generated in-situ for fluorometric determination of thrombin activity. Microchimica acta. 2019;186:657. DOI: 10.1007/s00604-019-3765-2

This article may be used for non-commercial purposes in accordance with Springer Terms and Conditions for Self-Archiving. 


\title{
CdS quantum dots generated in-situ for fluorometric determination of thrombin activity
}

\author{
Laura Saa ${ }^{\mathrm{a}}$, Beatriz Díez-Buitrago ${ }^{\mathrm{a}, \mathrm{b}}$, Nerea Briz ${ }^{\mathrm{b}}$, Valeri Pavlov $^{\mathrm{a} *}$
}

a Biosensing Laboratory. CIC biomaGUNE. Paseo Miramón 182, San Sebastián, 20014, Spain

b Tecnalia, Paseo Mikeletegi, San Sebastián, 20009, Spain

KEYWORDS Fibrinogen, biosensing, nanoparticles, human plasma, coagulation, ecarin, bioassay, emission, fibrin, alkaline phosphatase 


\begin{abstract}
A method is presented for sensitive determination of thrombin activity. It is based on (a) the interaction between fibrinogen after activation with thrombin, and (b) an enzymatic amplification step consisting of in-situ growth of CdS quantum dots (QDs). Fibrinogen is immobilized on the surface of the wells of a microplate and then incubated with a mixture of biotinylated fibrinogen and thrombin. Thrombin activates immobilized fibrinogen and free biotinylated fibrinogen. This leads to the formation of insoluble biotinylated fibrin that remains bound on the surface of the wells. Afterwards, the samples are incubated with avidin-labeled alkaline phosphatase (ALP) which binds to biotinylated fibrin. ALP hydrolyzes the substrate p-nitrophenyl phosphate (pNPP) under formation of phosphate ions which stabilize CdS QDs that are grown in-situ from cadmium(II) and sulfide. The generation of fibrin is correlated with the activity of thrombin. Increased thrombin concentration results in increased fluorescence that can be measured at excitation/emission wavelengths of 300/510 nm. The introduction of such an amplification step (the enzyme-triggered growth of QDs) allows for the quantification of thrombin in the picomolar concentration range, with a linear response up to $2.5 \mathrm{pM}$ and a detection limit of $0.05 \mathrm{pM}$. The method was applied to the determination of thrombin activity in human plasma and of the thrombin inhibitor argatroban.
\end{abstract}




\section{INTRODUCTION}

Thrombin is a crucial enzyme involved in the blood coagulation cascade and is also related to other physiological processes like the inflammatory response and tissue repair [1,2]. Thrombin is used in surgery as a very potent topical hemostat when surgical ligation of bleeding fails [3]. The quantitative determination of thrombin activity in body liquids is essential for clinical diagnosis[4], biochemical research [5], and production of thrombin-based hemostats. The interaction between thrombin and fibrinogen is part of the physiological process of blood clotting, in which thrombin, as a serine protease, selectively cleaves Arg-Gly bonds in fibrinogen [6] making it active for formation of a fibrin polymer, the main component of a clot [7]. In most cases thrombin is detected via affinity interactions with the thrombin DNA aptamers [8-11] but aptamer-based assays cannot distinguish between active and inactive thrombin. Given the fact that thrombin rapidly loses its activity in aqueous solutions, the aptamerbased methods are not suitable for determination of thrombin activity. The assays for thrombin based on measuring its catalytic activity towards formation of fibrin provide much more reliable information about the concentration of active thrombin.

Several assays based on interaction between thrombin and fibrinogen have been reported. The most common measurement for determination of fibrinogen is the Clauss fibrinogen assay where plasma is activated by thrombin and which is conducted by turbidimetric devices [12] or QCM-D [13]. In the last decades, nanomaterials have emerged as a powerful tool in the field of biosensing [14], and nanoparticles (NPs) of different size and nature have been successfully employed in bioassays for detection and quantification of coagulation related proteins, taking advantage of the physiological process of fibrin formation after activation of fibrinogen by thrombin. For example, a laser desorption/ionization mass spectrometry (LDI-MS) based approach using gold NPs adsorbed on mixed cellulose ester membrane modified with fibrinogen has been reported for monitoring thrombin generation and screening anticoag- 
ulants in human plasma.[15] Another biosensor based on gold NPs, employs fibrinogen modified gold NPs for the selective and sensitive analysis of thrombin and Factor Xa was based on the fact that thrombin-mediated cleavage of fibrinogen to fibrin induces the aggregation of the fibrinogen-coated Au NPs.[16-18] In a similar way, a colorimetric assay to detect fibrinogen in plasma via the fibrinogeninduced aggregation of thrombin-conjugated Au NPs Thr-Au NPs has been reported.[19] Water-soluble near infrared $\mathrm{CuInS}_{2}$ quantum dots (QDs) capped by mercaptopropionic acid [20] have been also used to monitor thrombin activity. The reported assay is based on the fluorescence quenching of the fibrinogen-CuInS 2 QDs complex triggered by thrombin. Thus, the increase in thrombin concentration is correlated with a decrease in the readout signal due to a quenching effect of the fibrin.

The previously mentioned methods for detection of thrombin employ presynthesized NPs involving several stages for their synthesis and subsequent modification with thrombin or fibrinogen and require additional time for preparation of nanomaterials. In addition the reproducibility of the assays for thrombin activity based on presynthesized NPs decorated with thrombin or fibrinogen depends significantly on the quality of NP preparation. Finally during the storage of these presynthesized nanomaterials, their biochemical activity can be decreased due to aggregation of NPs and denaturation of proteins. Our method is not based on any presynthesized nanomaterials and does not suffer from instability of modified presynthesized NPs. We employed in situ growth of CdS QDs (pioneered by us [21, 22] ) catalyzed by the enzyme. Alkaline phosphatase (ALP) is able to hydrolyze its substrate $p$-nitrophenyl phosphate to yield phosphate ions stabilizing formation of $\mathrm{CdS}$ QDs from $\mathrm{Cd}^{+2}$ and $\mathrm{S}^{-2}$ ions [23]. The novelty of our approach consists in formation of fibrin polymer decorated with biotin moieties combined with the enzymatic amplification. This double signal amplification approach allows for the sensitive detection of active thrombin taking advantage of the interaction between molecules of fibrinogen after activation with thrombin followed by an enzymatic amplification step. In the presence of thrombin, fibrinogen is converted into insoluble fibrin. Since the generation of fibrin is correlated with the activity of thrombin, 
an increase in thrombin concentration is related with an increase in the readout signal due to an amplified generation of fluorescent CdS QDs. The introduction of an amplification step based on the modulation of the enzymatic growth of CdS QDs allows the development of a sensitive bioassay for quantification of thrombin in the picomolar range. 


\section{EXPERIMENTAL}

Materials. Thrombin from human plasma, Fibrinogen from human plasma, Avidin Alkaline Phosphatase (Av-ALP), Ecarin from Echis carinatus, Human plasma, Tris(hydroxymethyl)aminomethane (Tris), 10x concentrated phosphate buffered saline (PBS), calcium chloride, potassium chloride, magnesium chloride and $p$-nitrophenyl phosphate were obtained from Sigma (www.sigmaaldrich.com, St. Louis, MO, USA). Sulfo-NHS-LC-Biotin was obtained from Thermo Fisher Scientific (www.thermofisher.com, Waltham, MA, USA). Milli-Q water was used in all experiments. Fluorescence measurements were performed in a Varioskan Flash microplate reader (Thermo Fisher Scientific) using 96-microwell black plates. Transmission electron microscopy images were collected with a JEOL JEM $2100 \mathrm{~F}$ operating at $120 \mathrm{kV}$.

Biotinylation of fibrinogen. Fibrinogen $\left(1 \mathrm{mg} \mathrm{mL}^{-1}\right.$ in PBS was incubated in the presence of 50-fold molar excess of Sulfo-NHS-LC-Biotin in water for 1h at RT. Afterwards, in order to eliminate the unreacted biotin reagent, the mixture was filtered an Amicon Ultra filter with a 100K molecular weight cutoff. The washed biotinylated fibrinogen was used in the subsequent experiments.

Thrombin detection assay. A 96-well NUNC Maxisorp microtiter plate was coated with Fibrinogen $\left(0.1 \mathrm{mg} \mathrm{mL}^{-1}\right)$ in PBS for overnight at $4{ }^{\circ} \mathrm{C}$. The plate was washed three times with PBS/0.05\% Tween 20 (PBST). Different concentrations of human thrombin in buffer A (Tris-HCl $5 \mathrm{mM}, 30 \mathrm{mM} \mathrm{NaCl}, 0.5$ $\mathrm{mM} \mathrm{CaCl} 2,1 \mathrm{mM} \mathrm{KCl}, 0.2 \mathrm{mM} \mathrm{MgCl}$, $\mathrm{pH}$ 7.4) were incubated for $1 \mathrm{~h}$ at $\mathrm{RT}$ in the presence of biotinylated fibrinogen $\left(0.01 \mathrm{mg} \mathrm{mL}^{-1}\right)$. After washing three times with PBST, avidin-labeled ALP (1:500 in PBS) was added to the wells and incubated for 30 min at RT. The plate was then washed three times with PBST and two times with $50 \mathrm{mM}$ Tris- $\mathrm{HCl}$ and $1 \mathrm{mM} \mathrm{MgCl}_{2}, \mathrm{pH} 8.8$. Then $100 \mu \mathrm{L}$ of ALP substrate $\left(0.5 \mathrm{mM}\right.$ pNPP in $50 \mathrm{mM}$ Tris-HCl buffer and $\left.1 \mathrm{mM} \mathrm{MgCl}_{2}, \mathrm{pH} 8.8\right)$ were added to each well and incubated for $90 \mathrm{~min}$ at $37^{\circ} \mathrm{C}$. After $90 \mu \mathrm{L}$ of each sample were drawn from the wells and placed to a 
black 96-well NUNC microtiter plate, $5 \mu \mathrm{L}$ of $10 \mathrm{mM} \mathrm{Na} 2 \mathrm{~S}$ and $5 \mu \mathrm{L}$ of $50 \mathrm{mM} \mathrm{Cd}\left(\mathrm{NO}_{3}\right)_{2}$ were added and the fluorescence emission spectra of the resulting suspension were recorded after 5 min at $\lambda$ ex $=300$ $\mathrm{nm}$. This assay is performed in vitro and the concentration of cadmium ions and generated volumes of CdS QDs are quite low. The formed residues are treated according to the standard laboratory protocols to eliminate poisonous materials before disposal in order to reduce environmental toxicity.

Detection of thrombin in human plasma. Diluted (1:50000) pooled human plasma (Sigma-Aldrich) was incubated in the presence of $0.2 \mathrm{nM}$ ecarin, $0.01 \mathrm{mg} \mathrm{mL}^{-1}$ biotinylated fibrinogen and different concentrations of thrombin for $1 \mathrm{~h}$ at RT in buffer A. After, the detection of the total amount of thrombin was performed as described above.

Detection of anticoagulant argatroban. Different concentrations of argatroban were incubated with thrombin $(2.5 \mathrm{pM})$ and biotinylated fibrinogen $\left(0.01 \mathrm{mg} \mathrm{mL}^{-1}\right)$ in buffer A for $1 \mathrm{~h}$ at RT. After, the detection of thrombin was performed as described above. 


\section{RESULTS AND DISCUSSION}

The principle of operation of our system is presented in Scheme 1. Thrombin enzyme is able to activate fibrinogen immobilized on the surface of a microplate and biotinylated fibrinogen in solution. The activated molecules can bind each other forming a fibrin fiber that remains bound on the surface of the microplate (Scheme 1, step 1 and 2).
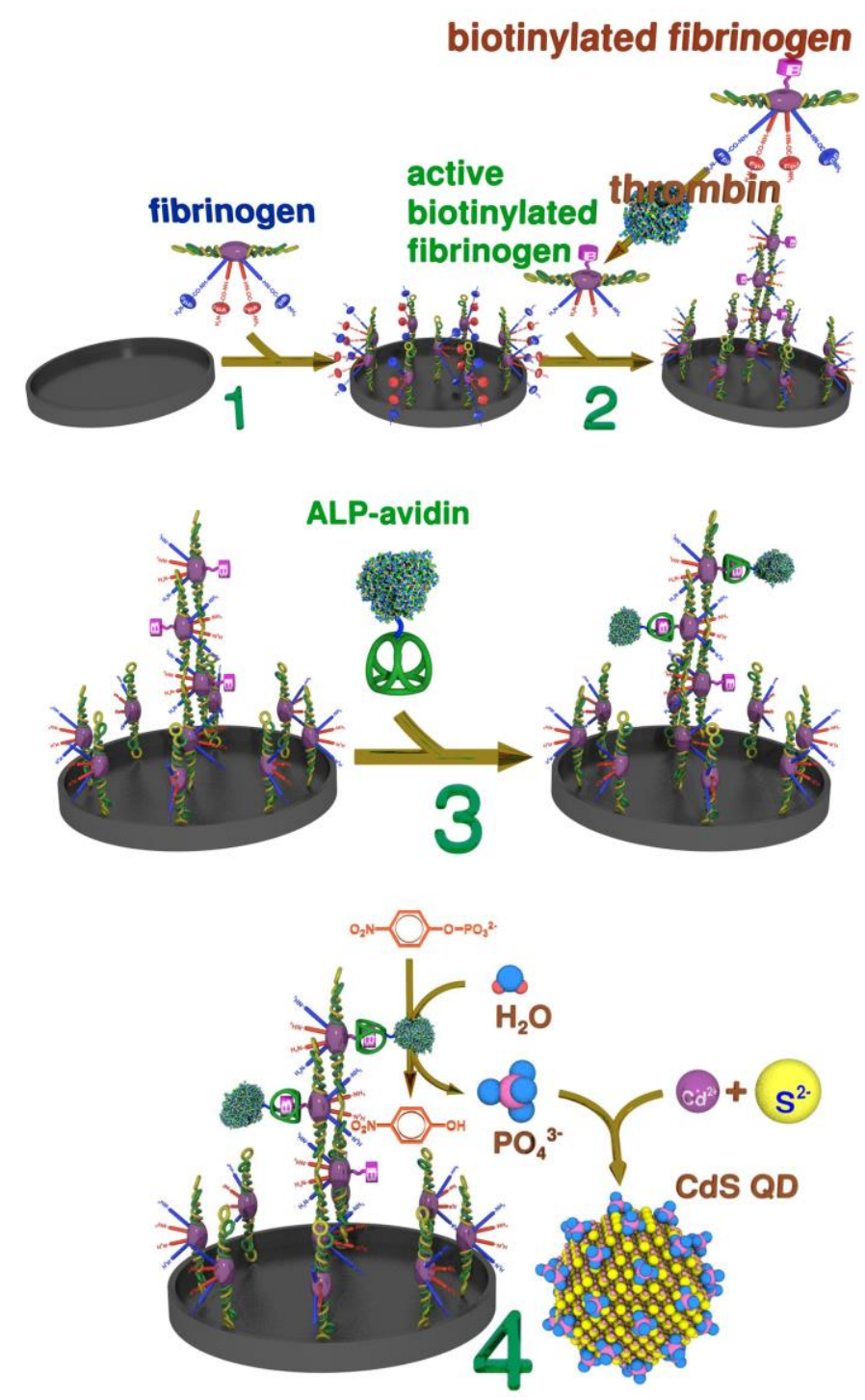

Scheme 1. Detection of thrombin based on the generation of phosphate stabilized CdS QDs. 
A schematic illustration of the fibrin formation process is shown in Scheme S1 in Electronic Supporting Material (ESM). Afterwards, the samples were incubated with avidin labeled ALP, which binds to the biotinylated fibrinogen molecules. (Scheme 1, step 3) The detection step was performed by using the substrate $p$-nitrophenyl phosphate (pNPP), which is cleaved by ALP, giving $p$-nitrophenol and phosphate ions as the products of the reaction. Upon the addition of $\mathrm{Cd}^{2+}$ and $\mathrm{S}^{2-}$ ions to the reaction mixture, phosphate-stabilized fluorescent nanocrystals of CdS are formed. (Scheme 1, Step 4) The formation of CdS QDs can be followed by fluorescence spectroscopy.

A number of control experiments were carried out in order to confirm the suggested mechanism of operation of the reported enzymatic analytical system (Figure 1). A significant growth in the fluorescence signal was only observed when all components of the assay were present in the mixture (Adsorbed fibrinogen, biotinylated fibrinogen, thrombin, Avidin-ALP, $\mathrm{Cd}\left(\mathrm{NO}_{3}\right)_{2}$ and $\mathrm{Na}_{2} \mathrm{~S}$ ) (Figure 1, curve a ). Whereas, if any of the components was absent, an insignificant increase of fluorescence was detected. (Figure 1A, curves b-e), confirming that all the components of the system are required to generate fluorescent CdS QDs in the assay. Transmission Electron Microscopy (TEM) was used in order to confirm the existence of stable CdS QDs in the reaction mixture (Figure 1B).

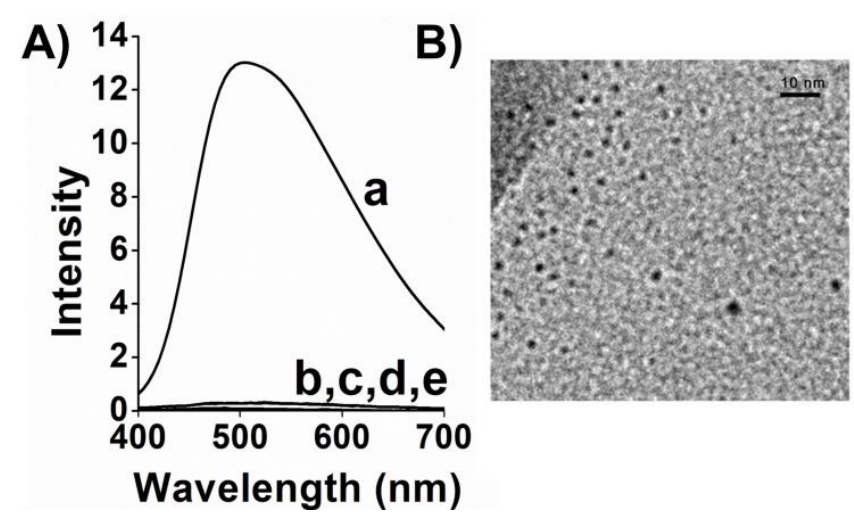


Figure 1. A) Emission spectra of CdS QDs formed in the system containing: a) Adsorbed fibrinogen (0.1 $\left.\mathrm{mg} \mathrm{mL} \mathrm{m}^{-1}\right)$, biotinylated fibrinogen $\left(0.01 \mathrm{mg} \mathrm{mL}^{-1}\right)$, Thrombin $(2.5 \mathrm{pM})$, Avidin-ALP (1:500), $\mathrm{Cd}\left(\mathrm{NO}_{3}\right)_{2}$ $(2.5 \mathrm{mM})$ and $\left.\mathrm{Na}_{2} \mathrm{~S}(0.5 \mathrm{mM}) ; \mathrm{b}\right)$ in the absence of Av-ALP; $)$ in the absence of adsorbed fibrinogen; d) in the absence of $\mathrm{Cd}\left(\mathrm{NO}_{3}\right)_{2}$; e) in the absence of $\mathrm{Na}_{2} \mathrm{~S}$. B) TEM images of the formed CdS QDs.

The images revealed the presence of spheroidal QDs with a medium diameter of $1.67 \pm 0.48 \mathrm{~nm}$. (ESM, Figure S1). The concentration of all the components of the assay and incubation times were optimized in order to get the highest signal to noise ratio. Thus, concentrations for an optimal operation of the system were determined to be $0.1 \mathrm{mg} \mathrm{mL}^{-1}$ adsorbed fibrinogen, $0.01 \mathrm{mg} \mathrm{mL}^{-1}$ biotinylated fibrinogen, Avidin-ALP 1:500, $2.5 \mathrm{mM} \mathrm{Cd}\left(\mathrm{NO}_{3}\right)_{2}$ and $0.5 \mathrm{mM} \mathrm{Na}_{2} \mathrm{~S}$.

Afterwards, we investigated the effect of thrombin concentration on the generation of fluorescent QDs. Figure 2A displays the emission of the CdS QDs formed in the system containing fixed concentrations of fibrinogen and varying amounts of thrombin.
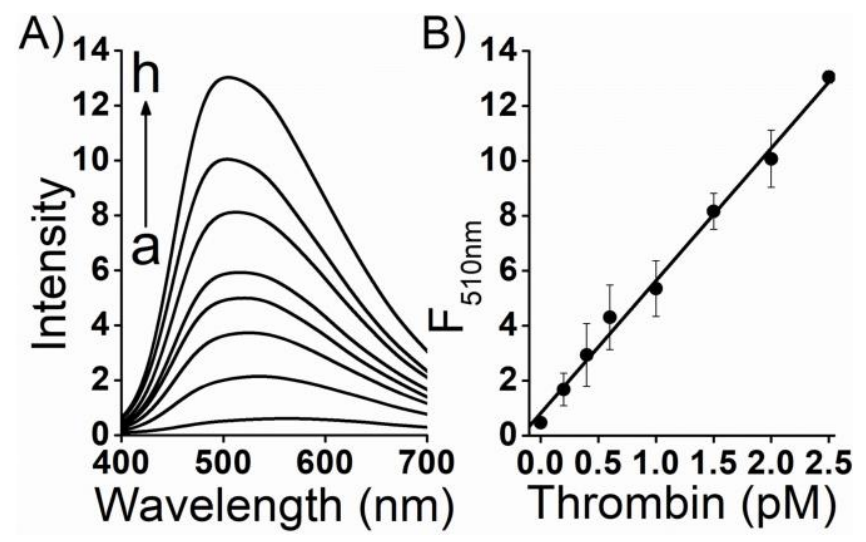

Figure 2. A) Emission spectra of CdS QDs formed in the system containing adsorbed fibrinogen, biotynilated fibrinogen, Avidin-ALP, $\mathrm{Cd}\left(\mathrm{NO}_{3}\right)_{2}, \mathrm{Na}_{2} \mathrm{~S}$ and different concentrations of thrombin. B) Calibration plot of thrombin at $\lambda \mathrm{em}=510 \mathrm{~nm}$. 
We observed from the spectra that increasing concentrations of thrombin are directly related with an increase in the emission peak of the formed CdS QDs. The experimental results correlate well with the mechanism depicted in Scheme 1. Thrombin activates fibrinogen on the surface on the microplate and biotinylated fibrinogen in solution. When the concentration of thrombin in the assay increases, the amount of biotinylated fibrinogen that remains bound on the well also increases, leading to a higher fluorescent signal after the enzymatic amplification step by ALP. In the absence of thrombin, the activation of fibrinogen does not occur, and no fluorescent signal is detected. Figure 2B shows a linear response up to $2.5 \mathrm{pM}$ of thrombin, with a limit of detection (LOD) of $0.05 \mathrm{pM}$ (3stdev of the blank). At least three independent measurements were performed at each point and the calculated mean RSD was 9.8\% confirming good reproducibility of this assay. This LOD is lower than previously reported QD based assays for detection of thrombin. [20, 24, 25] Table 1 contains comparison with other previously reported nanomaterial-based methods for detection of thrombin. 
Table 1. Comparison of other nanomaterial-based assays for detection of thrombin.

\begin{tabular}{lccccc}
\hline $\begin{array}{c}\text { Method } \\
\text { applied }\end{array}$ & Materials used & LOD & Linear range & $\begin{array}{c}\text { Measuring } \\
\text { Thr activity }\end{array}$ & Reference \\
\hline Colorimetry & Au NP & $1 \mathrm{pM}$ & $4-60 \mathrm{pM}$ & yes & {$[18]$} \\
\hline Colorimetry & AuNP & $0.1 \mathrm{nM}$ & $0.1-15 \mathrm{nM}$ & no & {$[26]$} \\
\hline Colorimetry & AuNP & $0.04 \mathrm{pM}$ & $0.1-10 \mathrm{pM}$ & yes & {$[17]$} \\
\hline Colorimetry & $\begin{array}{c}\text { Pt NP -metal organic } \\
\text { framework }\end{array}$ & $1.67 \mathrm{pM}$ & $0.0005-1 \mathrm{nM}$ & no & {$[27]$} \\
\hline Electrochemistry & $\begin{array}{c}\text { Pt NP -metal organic } \\
\text { framework }\end{array}$ & $0.333 \mathrm{fM}$ & $1 \mathrm{fM}-10 \mathrm{nM}$ & no & [27] \\
\hline Electrochemistry & AuNPs/MoS & $0.027 \mathrm{fM}$ & $0.1 \mathrm{fM}-0.1 \mathrm{nM}$ & no & {$[28]$} \\
\hline Fluorescence & CuInS 2 QDs & $8.7 \mathrm{pM}$ & $0.067-390 \mathrm{nM}$ & yes & {$[20]$} \\
\hline Fluorescence & $\begin{array}{c}\text { carboxyl Qdots } 655 \\
\text { ITK }\end{array}$ & $2.6 \mathrm{nM}$ & $5.0-500 \mathrm{nM}$ & no & [24] \\
\hline Fluorescence & CdTe QDs & $0.70 \mathrm{nM}$ & $1.4-21 \mathrm{nM}$ & no & {$[25]$} \\
\hline Phosphorescence & Mn-doped ZnS QDs & $15.26 \mathrm{pM}$ & $0.06-2 \mathrm{nM}$ & no & {$[29]$} \\
\hline Fluorescence & CdS QDs & $0.05 \mathrm{pM}$ & $0.05-2.5 \mathrm{pM}$ & yes & This work \\
\hline
\end{tabular}

Furthermore, we compared our method with the standard chromogenic pNPP assay used for the detection of ALP. Figure S2 in ESM shows the calibration plots of normalized fluorescence/absorbance signal versus thrombin concentration. Thus, the sensitivity of the system was significantly improved by the growth of QDs in situ. The previously reported prothrombin (proenzyme of thrombin) concentrations in human plasma and consequently human thrombin concentrations which can be detected in human plasma are between 86 and $117 \mu \mathrm{g}$ per $\mathrm{mL}$ (1.2-1.6 micromolar concentration). [30,31] Due to high sensitivity and low detection limit of the assay, the volume of plasma samples can be reduced. This allows the use of very diluted concentration of plasma which may be useful for biological research in which the volume of sample is limited. We proved it by dilution of human plasma by 500-1000 times. Usually thrombin in human plasma is inactive in the form of prothrombin. In order to test the ability of this as- 
say to detect thrombin in complex matrixes, we added a known concentration of $2.5 \mathrm{pM}$ of thrombin to 500 and 1000 fold diluted plasma and fluorescence of the generated CdS QDs were recorded. The recoveries of thrombin from spiked plasma samples were determined based on the calibration plot using pure thrombin in buffer (Figure 2). A recovery of 114\% was obtained at 500 fold diluted plasma, and 106\% was obtained at 1000 fold diluted plasma.

Detection of thrombin inhibitors. We showed that thrombin activity can be correlated with an increase of fluorescence in the system. As the amount of in situ generated CdS QDs directly depends on the thombin activity, this method can be applied for developing a fluorogenic method for detecting thrombin inhibitors. This is extremely relevant from the clinical point of view, as monitoring the anticoagulant activity of some drugs is required for patients with bleeding disorders. In order to prove the performance of our system for detecting thrombin inhibitors, we chose the compound argatroban. It is a smallmolecule that acts as a reversible thrombin inhibitor, selective for the catalytic site of thrombin, offering the potential for significant antithrombotic efficacy with minimal systemic anticoagulant effects [32].

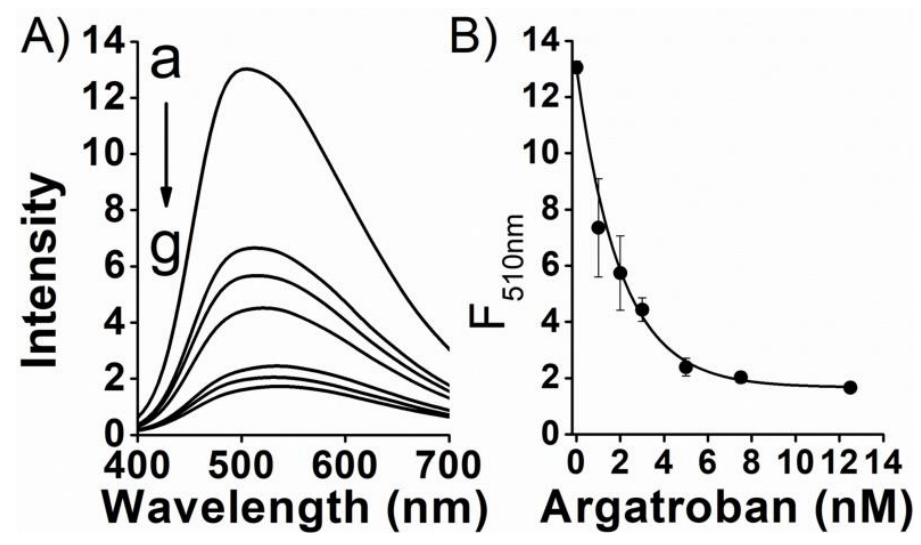

Figure 3. A) Emission spectra of CdS QDs formed in the system containing adsorbed fibrinogen, biotynilated fibrinogen, Thrombin, Avidin-ALP, $\mathrm{Cd}\left(\mathrm{NO}_{3}\right)_{2}$ and $\mathrm{Na}_{2} \mathrm{~S}$ and different concentrations of argatroban. B) Calibration plot of Argatroban at $\lambda \mathrm{em}=510 \mathrm{~nm}$. 
In order to investigate the effect on argatroban in the assay, we incubated a fixed concentration of thrombin in the presence of different concentrations of argatroban. Figure 3 shows the effect of the inhibitor on the recorded fluorescent signal. An increase in the concentration of argatroban is correlated with a decrease of the fluorescence intensity. As thrombin activity is inhibited, the amount of biotinylated fibrin that remains in the wells decreases, leading to a less amount of CdS QDs generated by ALP after the amplification step. Control experiments performed by adding the inhibitor in the absence of thrombin, showed that argatroban does not interfere in the readout fluorescent signal (Figure S3 in ESM).

Detection of thrombin generated by ecarin in plasma. Usually plasma does not contain thrombin which is generated only during initiation of coagulation process with participation of Factor Xa and other different blood factors. Ecarin, the primary reagent in the venom of the saw-scaled viper, Echis carinatus, activates thrombin cleaving the Arg-Ile bond in the precursor prothrombin to form meizothrombin, which by autocatalysis is subsequently converted to meizothrombin 1 and finally into $\alpha$ thrombin[33]. Therefore, ecarin can be used to produce thrombin from its proenzyme prothrombin in human plasma[34]. First we preincubated human plasma with ecarin to produce active thrombin. Next, we applied the standard addition method for detection of resulting thrombin. Varying standard known amounts of human thrombin were injected into the samples with human plasma and ecarin to obtain the plot shown in Figure 4 (circles). Next, calibration plot was obtained with different amount of added human thrombin to human plasma (squares). 


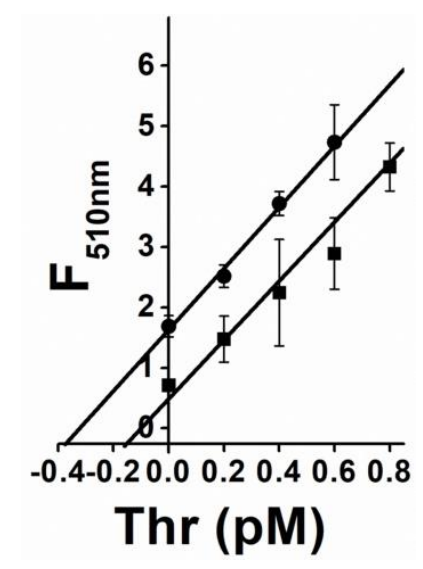

Figure 4. Calibration plot of thrombin in diluted human plasma in the absence (squares) or presence (circles) of $0.2 \mathrm{nM}$ ecarin.

From this plot, we found intercept of the calibration line observed in the presence of ecarin with the $\mathrm{x}$ axis showing the content of thrombin produced in human plasma by ecarin without added standard. The difference calculated between this intercept and the one found from the second calibration line produced in the absence of ecarin in human plasma showed a concentration of $0.221 \mathrm{pM}$ of thrombin which corresponds to $11 \mathrm{nM}$ of thrombin generated by ecarin in the assay under the given experimental conditions. Given the fact that the linear range of our assay is from 0.05 to $2.5 \mathrm{pM}$ of thrombin, the human plasma samples should be diluted by 50000 times for measurements. The dilution factor was considered to calculate the concentration of thrombin partially generated in plasma sample. This concentration of thrombin is within the range of thrombin concentration usually measured in clinical laboratories. $[35,36]$ The method of standard addition by its nature allows to perform analysis even in the presence of possible interferences in the analytical matrix such as human plasma.[37]

Conclusions. We introduced a method for direct detection of thrombin employing enzymatic in situ generation of CdS QDs. This assay is based on the highly specific interaction between thrombin and 
fibrinogen and the fibrin formation process. Employment of biotinylated fibrinogen to form biotinylated fibrin with high affinity to Avidin-ALP, allows immobilizing ALP on the microplate surface. ALP activity modulates the formation of fluorescent CdS QDs in situ as a function of active thrombin concentration. This allows evaluation of the capacity of thrombin to convert fibrinogen to fibrin and in general, detect diseases related with coagulation abnormalities caused by thrombin.

The reproducibility of the previously reported methods for thrombin activity based on presynthesized NPs modified with thrombin or fibrinogen significantly depends on the stability and the quality of employed nanomaterials. During storage those nanomaterials can lose their biochemical properties due to unavoidable aggregation of NPs and denaturing of the decorating proteins. Our method employs fresh materials for preparation of CdS QDs and does not suffer from aggregation of NPs because they are produced in situ and do not lose their fluorescent properties during their formation and existence in the analytical mixture $(5 \mathrm{~min})$ needed to obtain the fluorescence readout signal. In this assay millimolar concentrations of cadmium ions are used to produce CdS QDs in situ for sensitive detection of thrombin activity. Due to its toxicity, it is desirable to substitute these cations by less toxic material in future assays. This fluorogenic detection employing enzymatically generated CdS QDs yields a bionalytical assay with better detection limits in comparison with those of the previously published methods for active thrombin detection based on QDs. Our methodology allows for the sensitive detection of active thrombin generated in plasma and thrombin inhibitors. We believe that our sensitive method allows to use smaller volumes of thrombin preparation samples in quantitative determination of thrombin activity in body liquids for clinical diagnosis, biochemical research, and production of thrombin-based hemostats. 


\section{ASSOCIATED CONTENT}

Electronic Supporting Material.. Size distribution of the CdS QDs, comparison between colorimetric and fluorogenic methods and effect of argatroban on the detection system.

\section{AUTHOR INFORMATION}

\section{Corresponding Author}

* Valeri Pavlov vpavlov@,cicbiomagune.es

\section{Author Contributions}

The manuscript was written through contributions of all authors. All authors have given approval to the final version of the manuscript.

\section{Acknowledgments}

This work was supported by the Ministry of Science, Innovation and Universities/AEI/FEDER, UE (RETOS I+D - Grant No.BIO2017-88030-R and the Maria de Maeztu Units of Excellence Programme - Grant No. MDM-2017-0720).

\section{Compliance with ethical standards}

The author(s) declare that they have no competing interests.

\section{REFERENCES}

1. Becker RC, Spencer FA (1998) Thrombin: Structure, Biochemistry, Measurement, and Status in Clinical Medicine. J Thromb Thrombolysis 5:215-229 . doi: 10.1023/A:1008843925851

2. Strukova SM (2001) Thrombin as a Regulator of Inflammation and Reparative Processes in 
Tissues. Biochem 66:8-18 . doi: 10.1023/A:1002869310180

3. Weaver F, Sung W. Ham, Wesley K. Lew (2010) Thrombin use in surgery: an evidence-based review of its clinical use. J Blood Med 1:135-142 . doi: 10.2147/JBM.S6622

4. Bichler J, Heit JA, Owen WG (1996) Detection of thrombin in human blood by ex-vivo hirudin. Thromb Res 84:289-294 . doi: 10.1016/S0049-3848(96)00189-2

5. Wolberg AS (2007) Thrombin generation and fibrin clot structure. Blood Rev 21:131-142 . doi: 10.1016/j.blre.2006.11.001

6. Chang J-Y (1985) Thrombin specificity. Eur J Biochem 151:217-224 . doi: 10.1111/j.14321033.1985.tb09091.x

7. Yang Z, Mochalkin I, Doolittle RF (2000) A model of fibrin formation based on crystal structures of fibrinogen and fibrin fragments complexed with synthetic peptides. Proc Natl Acad Sci 97:14156-14161 . doi: 10.1073/pnas.97.26.14156

8. Pavlov V, Xiao Y, Shlyahovsky B, Willner I (2004) Aptamer-functionalized Au nanoparticles for the amplified optical detection of thrombin. J Am Chem Soc 126:11768-11769 . doi: $10.1021 / \mathrm{ja} 046970 \mathrm{u}$

9. Chen YX, Huang KJ, He LL, Wang YH (2018) Tetrahedral DNA probe coupling with hybridization chain reaction for competitive thrombin aptasensor. Biosens Bioelectron 100:274281 . doi: 10.1016/j.bios.2017.09.022

10. Li J, Jiao Y, Liu Q, Chen Z (2018) Colorimetric Detection of Thrombin Based on Intensity of Gold Nanoparticle Oligomers with Dark-Field Microscope. ACS Sustain Chem Eng 6:6738-6745 . doi: 10.1021/acssuschemeng.8b00521

11. Wen D, He M, Ma K, Cui Y, Kong J, Yang H, Liu Q (2018) Highly sensitive fluorometric determination of thrombin by on-chip signal amplification initiated by terminal deoxynucleotidyl transferase. Microchim Acta 185:380 . doi: 10.1007/s00604-018-2903-6 
12. Mackie IJ, Kitchen S, Machin SJ, Lowe GDO (2003) Guidelines on fibrinogen assays. Br J Haematol 121:396-404 . doi: 10.1046/j.1365-2141.2003.04256.x

13. Oberfrank S, Drechsel H, Sinn S, Northoff H, Gehring FK (2016) Utilisation of quartz crystal microbalance sensors with dissipation (QCM-D) for a clauss fibrinogen assay in comparison with common coagulation reference methods. Sensors 16:282 . doi: 10.3390/s16030282

14. Hou S, Zhang A, Su M (2016) Nanomaterials for Biosensing Applications. Nanomaterials 6:58 . doi: 10.3390/nano6040058

15. Li YJ, Chiu WJ, Unnikrishnan B, Huang CC (2014) Monitoring thrombin generation and screening anticoagulants through pulse laser-induced fragmentation of biofunctional nanogold on cellulose membranes. ACS Appl Mater Interfaces 6:15253-15261 . doi: 10.1021/am503615c

16. Niu Y, Wang P, Zhao Y, Fan A (2013) Turn-on colorimetric sensor for ultrasensitive detection of thrombin using fibrinogen-gold nanoparticle conjugate. Analyst 138:1475-1482 . doi: $10.1039 / \mathrm{c} 2 \mathrm{an} 36269 \mathrm{~d}$

17. Chen C-K, Huang C-C, Chang H-T (2010) Label-free colorimetric detection of picomolar thrombin in blood plasma using a gold nanoparticle-based assay. Biosens Bioelectron 25:19221927 . doi: 10.1016/j.bios.2010.01.005

18. Lin J-H, Huang K-H, Zhan S-W, Yu C-J, Tseng W-L, Hsieh M-M (2019) Inhibition of catalytic activity of fibrinogen-stabilized gold nanoparticles via thrombin-induced inclusion of nanoparticle into fibrin: Application for thrombin sensing with more than 104-fold selectivity. Spectrochim Acta Part A Mol Biomol Spectrosc 210:59-65 . doi: 10.1016/j.saa.2018.11.013

19. Chen YY, Tseng CW, Chang HY, Hung YL, Huang CC (2011) Gold nanoparticle-based colorimetric assays for coagulation-related proteins and their inhibition reactions. Biosens Bioelectron 26:3160-3166 . doi: 10.1016/j.bios.2010.12.019

20. Gao X, Liu X, Lin Z, Liu S, Su X (2012) CuInS2 quantum dots as a near-infrared fluorescent 
probe for detecting thrombin in human serum. Analyst 137:5620-5624 . doi: $10.1039 / \mathrm{c} 2 \mathrm{an} 35888 \mathrm{c}$

21. Saa L, Pavlov V (2012) Enzymatic growth of quantum dots: Applications to probe glucose oxidase and horseradish peroxidase and sense glucose. Small 8:3449-3455 . doi: 10.1002/smll.201201364

22. Garai-Ibabe G, Möller M, Pavlov V (2012) Ultrasensitive assay for detection of serum paraoxonase by modulating the growth of fluorescent semiconductor nanoparticles. Anal Chem 84:8033-8037 . doi: 10.1021/ac3018857

23. Malashikhina N, Garai-Ibabe G, Pavlov V (2013) Unconventional application of conventional enzymatic substrate: First fluorogenic immunoassay based on enzymatic formation of quantum dots. Anal Chem 85:6866-6870 . doi: 10.1021/ac4011342

24. Yin J, Zhang A, Dong C, Ren J (2015) An aptamer-based single particle method for sensitive detection of thrombin using fluorescent quantum dots as labeling probes. Talanta 144:13-19 . doi: 10.1016/j.talanta.2015.05.034

25. Zhang X, Hu R, Shao N (2013) Label-free sensing of thrombin based on quantum dots and thrombin binding aptamer. Talanta 107:140-145 . doi: 10.1016/j.talanta.2013.01.003

26. Chen Z, Tan L, Hu L, Zhang Y, Wang S, Lv F (2016) Real Colorimetric Thrombin Aptasensor by Masking Surfaces of Catalytically Active Gold Nanoparticles. ACS Appl Mater Interfaces 8:102_ 108 . doi: 10.1021/acsami.5b08975

27. Cheng T, Li X, Huang P, Wang H, Wang M, Yang W (2019) Colorimetric and electrochemical (dual) thrombin assay based on the use of a platinum nanoparticle modified metal-organic framework (type Fe-MIL-88) acting as a peroxidase mimic. Microchim Acta 186:94 . doi: $10.1007 / \mathrm{s} 00604-018-3209-4$

28. Shuai H-L, Wu X, Huang K-J (2017) Molybdenum disulfide sphere-based electrochemical 
aptasensors for protein detection. J Mater Chem B 5:5362-5372 . doi: 10.1039/C7TB01276D

29. Xiong Y, Liang M, Cheng Y, Zou J, Li Y (2019) An "off-on” phosphorescent aptasensor for the detection of thrombin based on PRET. Analyst 144:161-171 . doi: 10.1039/C8AN01571F

30. Lox CD, Strohm GH, Corrigan Jr JJ (1978) Radioimmunoassay of human prothrombin-The quantitation of plasma factor II antigen. Am J Hematol 4:261-267 . doi: 10.1002/ajh.2830040308

31. Koldas M, Uras F (2001) Avidin-biotin ELISA for measurement of prothrombin in human plasma. Thromb Res 102:221-227 . doi: 10.1016/S0049-3848(01)00257-2

32. Hursting MJ, Alford KL, Becker JP, Brooks RL, Joffrion JL, Knappenberger GD, Kogan PW, Kogan TP, Mckinney AA, Schwarz RP (1997) Novastan® (Brand of Argatroban): A SmallMolecule, Direct Thrombin Inhibitor. Semin Thromb Hemost 23:503-516 . doi: 10.1055/s-2007996128

33. Morita T, Iwanaga SBT-M in E (1981) Prothrombin activator from Echis carinatus venom. In: Proteolytic Enzymes, Part C. Academic Press, pp 303-311

34. Virel A, Saa L, Pavlov V (2012) Quantification of prothrombin in human plasma amplified by autocatalytic reaction. Anal Chem 84:2380-2387 . doi: 10.1021/ac203138y

35. Hemker HC, Giesen P, Al Dieri R, Regnault V, De Smedt E, Wagenvoord R, Lecompte T, Béguin S (2003) Calibrated automated thrombin generation measurement in clotting plasma. Pathophysiol Haemost Thromb 33:4-15 . doi: 10.1159/000071636

36. Hemker HC, Giesen P, Aldieri R, Regnault V, Smed E De, Wagenvoord R, Lecompte T, Béguin S (2002) The Calibrated Automated Thrombogram (CAT): a universal routine test for hyper- and hypocoagulability. Pathophysiol Haemost Thromb 32:249-253

37. Danzer K, Currie LA (1998) Guidelines for calibration in analytical chemistry. Part I. Fundamentals and single component calibration (IUPAC Recommendations 1998). Pure Appl Chem 70:993-1014 . doi: 10.1351/pac199870040993 


\section{Graphical abstract}

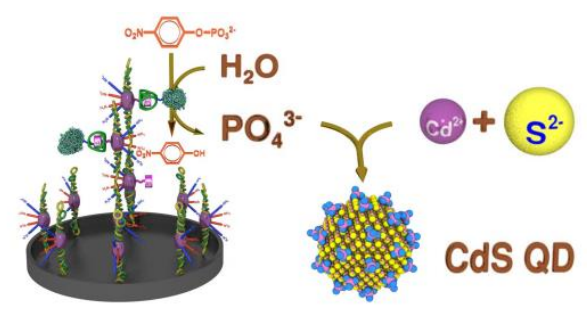

Schematic presentation of a method for determination of thrombin activity in the picomolar concentration range based on the interaction between fibrinogen after activation with thrombin, and an enzymatic amplification step consisting of in-situ growth of CdS quantum dots (CdS QD). 


\title{
Electronic Supporting Material
}

\section{CdS quantum dots generated in-situ for fluorometric determination of thrombin activity}

\author{
Laura Saa $^{\mathrm{a}}$, Beatriz Díez-Buitrago ${ }^{\mathrm{a}, \mathrm{b}}$, Nerea Briz ${ }^{\mathrm{b}}$,Valeri Pavlov ${ }^{\mathrm{a} *}$
}

a Biosensing Laboratory. CIC biomaGUNE, Paseo Miramón 182, San Sebastián, 20014, Spain

b Tecnalia, Paseo Mikeletegi, San Sebastián, 20009, Spain 


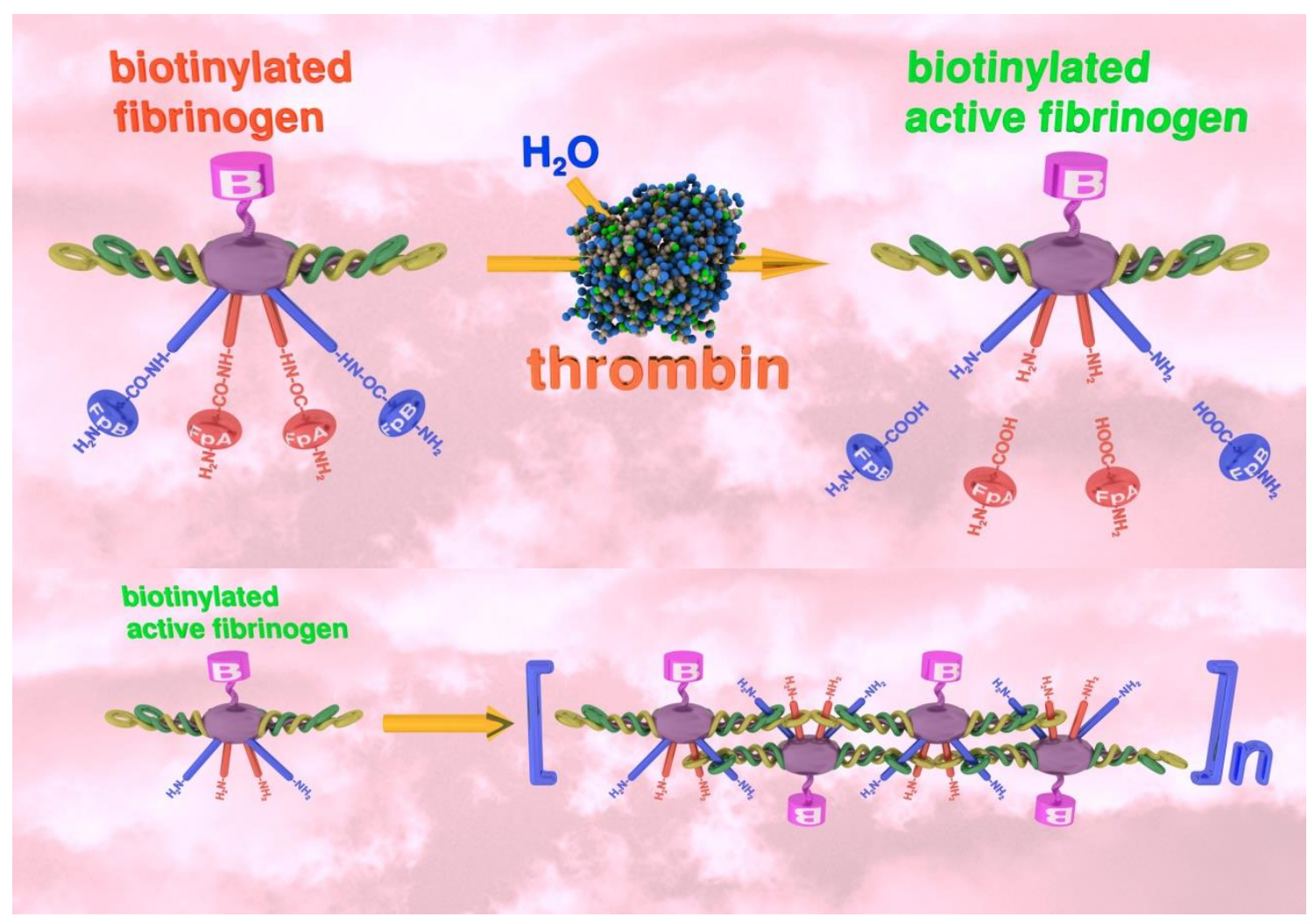

Scheme S1. Formation of biotinylated fibrin.

Thrombin enzyme is able to activate fibrinogen immobilized on the surface of a microplate and biotinylated fibrinogen in solution. The activated molecules can bind each other forming a biotinylated fibrin fiber that remains bound on the surface of the microplate. 


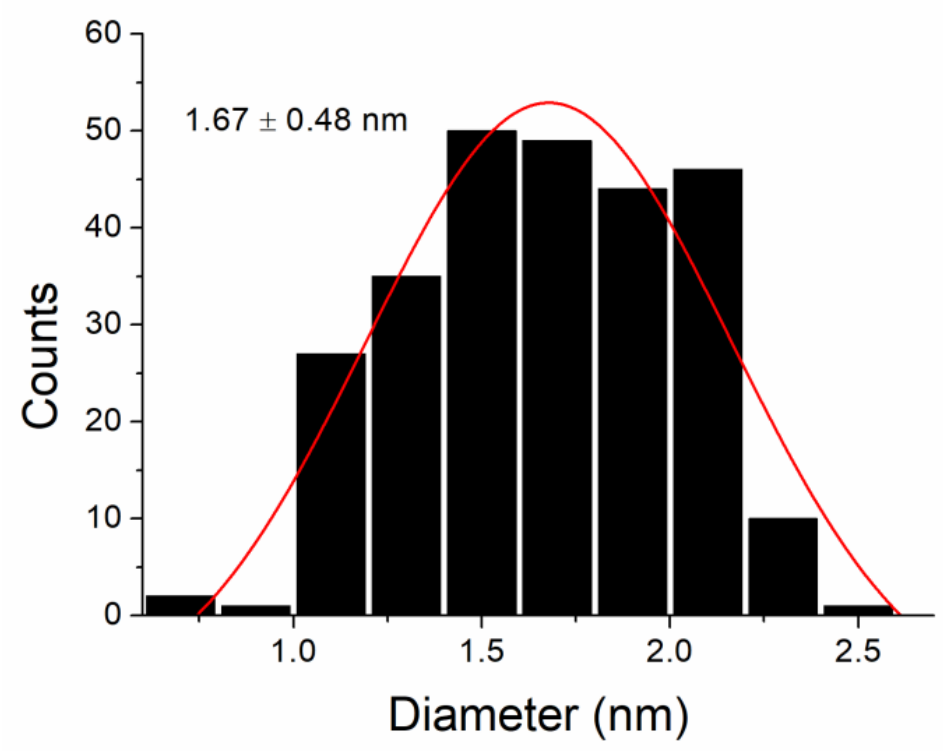

Figure S1. Size distribution of the formed phosphate stabilized CdS QDs.

Transmission Electron Microscopy (TEM) was used in order to confirm the existence of stable CdS quantum dots (QDs) in the reaction mixture. The images revealed the presence of spheroidal QDs with a medium diameter of $1.67 \pm 0.48 \mathrm{~nm}$. 


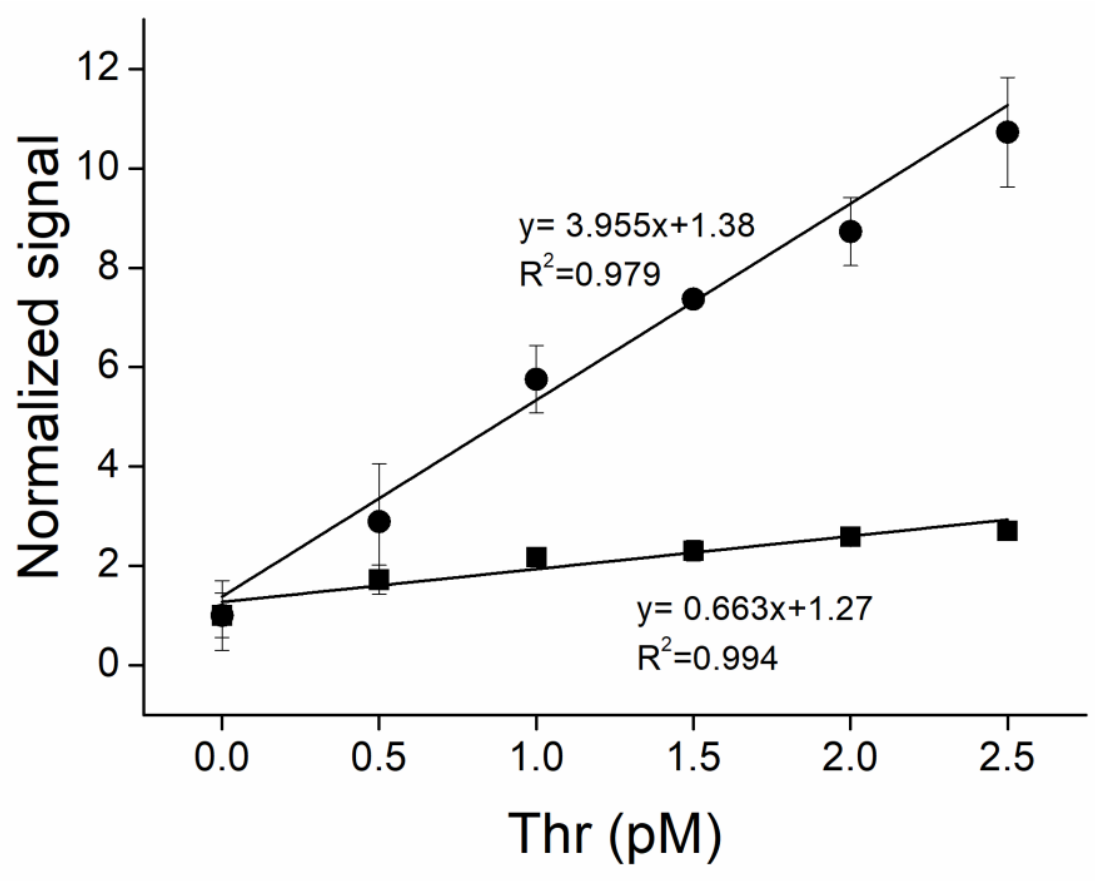

Figure S2. Calibration plot of thrombin measured by the CdS QD-based method (circles) and colorimetric pNPP-based method (squares).

We compared our method with the standard chromogenic pNPP assay used for the detection of alkaline phosphatase (ALP). Figure S2 shows the calibration plots of normalized fluorescence/absorbance signal versus thrombin concentration. Therefore, the sensitivity of the system was significantly improved by the growth of QDs in situ. 


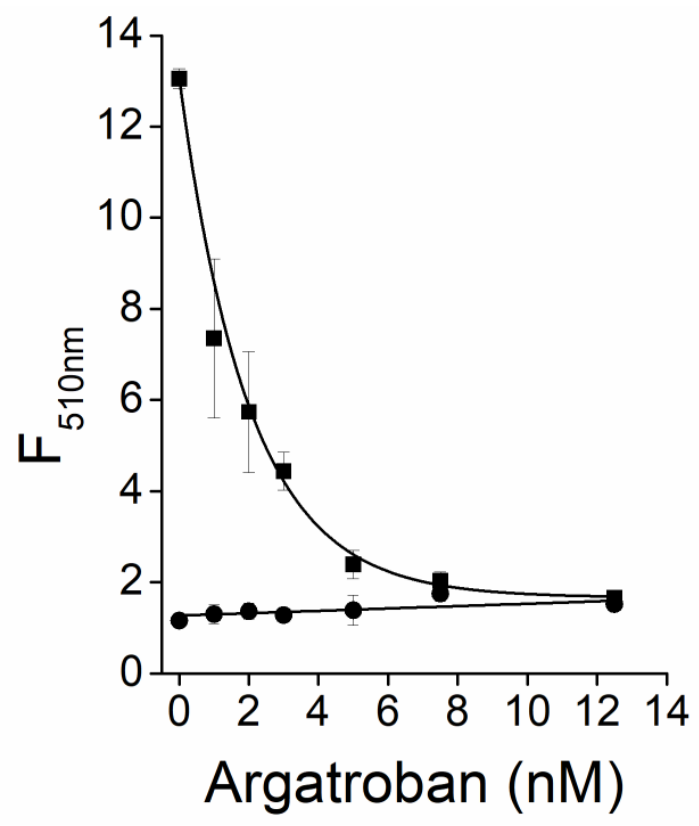

Figure S3. Effect of argatroban in the system in the presence (squares) or absence (circles) of thrombin.

An increase in the concentration of argatroban is correlated with a decrease of the fluorescence intensity (squares in Figure S3). As thrombin activity is inhibited, the amount of biotinylated fibrin that remains in the wells decreases, leading to a less amount of CdS QDs generated by ALP after the amplification step. Control experiments performed by adding the inhibitor in the absence of thrombin (Circles in Figure S3), showed that argatroban does not interfere in the readout fluorescent signal. 